\title{
Personality Traits dan Dukungan Sosial sebagai Prediktor Service Orientation Tenaga Kesehatan
}

\author{
Fadhilah Ahmad Qaniah*, Vifi Nurwianti* \\ *Fakultas Psikologi, Universitas Indonesia \\ Email:qaniah13@gmail.com
}

\section{ABSTRACT}

At this pandemic of COVID-19, it seems that everything related to service quality is very important. The transformation of the quality of health services should not only look at the experiences felt by patients. But also the experience of the health worker. There are two factors that influence aspects of service orientation: intrapersonal factors and interpersonal factors. Personality traits are one of the intrapersonal factors in how people provide health services differently. Meanwhile, the interpersonal factor that can be accessed easily are social support comes from family, friends, and significant others. However, research related to service, personality and social support together has never been carried out in Indonesia. Sample participants were 218 health workers from various professions / occupations in accordance with Law number 36 of 2014. The study used quantitative methods using linear regression analysis techniques. The results of the research findings showed that the effectiveness of personality traits (adjusted $R 2$ $=0.309$ ) and the quality of social support (adjusted $R 2=0.166$ ) could significantly predict $(p<0.01)$ the quality of service orientation of health worker. On personality traits, agreeableness and conscientiousness were the prediction of service orientation. On social support dimension, support from significant others and friend are stronger affect of service orientation. Thus, it can be concluded that two variables are predictors of service orientation.
Keywords: Service orientation, personality traits, social support, health worker.

\section{PENDAHULUAN}

Pada saat pandemi COVID-19, nampaknya segala hal terkait kualitas mutu pelayanan sangatlah penting. Fasilitas pelayanan kesehatan umumnya mulai memikirkan cara berbeda yang akan diambil untuk tetap merawat pasien dengan risiko penularan seminimal mungkin. Hal tersebut akan mengubah banyak hal termasuk prosedur penerimaan pasien dengan penggunaan masker, proses skrining yang lebih ketat, jadwal kunjungan, bahkan fasilitas khusus untuk beberapa pasien yang membutuhkan ${ }^{1}$.

Penelitian terkait mutu layanan kesehatan tidak lepas dari persepsi pasien yang diperoleh berdasarkan pengalaman, misalnya ketika berinteraksi dengan tenaga kesehatan atau nakes. Penelitian menunjukkan bahwa service orientation tenaga kesehatan atau nakes mempengaruhi secara langsung kepuasan dan loyalitas pasien, pandangan atau sikap pasien terhadap institusi kesehatan, dan serta berbagai dampak baik lainnya ${ }^{2-4}$. Service orientation yang dilakukan nakes juga mampu meningkatkan kepuasan pasien terhadap sarana prasarana yang dimiliki institusi ${ }^{5}$.

Service orientation pada riset ini mengambil pendapat Brown dkk. dan juga Kosker dkk., yakni keinginan karyawan untuk membantu dalam pemenuhan kebutuhan client atau pelanggan, dan merasa puas setelah memberikan layanan ${ }^{5-6}$. Menurut berbagai ahli, institusi kesehatan seperti 
rumah sakit, klinik, apotek, dan puskesmas sekarang berusaha membuat strategi dan sistem baru yang lebih berfokus pada kebutuhan pasien (patient-centered care) dengan cara meningkatkan service orientation. Semakin berkembangnya teknologi kesehatan, munculnya ekspektasi baru, kebutuhan-kebutuhan yang semakin beragam, serta pelatihan baru terkait peningkatan mutu pelayanan diharapkan dapat memicu berbagai pengalaman positif pasien ${ }^{7}$.

Pada tingkat individu, service orientation meningkatkan kepuasan kerja nakes ketika melakukan berbagai upaya kesehatan. Kepuasan kerja yang timbul juga akan berpengaruh kepada pelayanan yang lebih baik serta lebih memaknai nilai-nilai organisasi yang mana akan berpengaruh pada persepsi pasien dan profit/keuntungan rumah sakit. Pada tingkat organisasi, service orientation adalah salah satu elemen kunci yang bertanggungjawab menciptakan budaya yang mendorong inisiatif tenaga kesehatan atau nakes dan pemberian reward bagi pekerja dengan pelayanan berkualitas tinggi $6,8,9$.

Ada dua faktor yang mempengaruhi service orientation: faktor (a) intrapersonal dan (b) interpersonal. Big five personality traits adalah salah satu faktor intrapersonal terpenting bagaimana orang memberikan layanan kesehatan ${ }^{6,10,11}$. Sedangkan salah satu faktor interpersonal ialah berbagai bentuk dukungan sosial dari keluarga, teman, dan sahabat ${ }^{12-13}$. Ada lima sifat kepribadian pada big five personality traits; yaitu sifat conscientiousness, extraversion, agreeableness, openness, dan emotional stability atau neuroticism.

Conscientiousness merupakan sifat kepribadian yang cenderung teliti, mudah mengontrol impuls, dan gigih dalam mengejar tujuan. Extraversion merupakan sifat yang dikarakteristikkan dengan mudah tertarik, senang berbicara, asertif, mudah mengekspresikan emosinya ${ }^{14}$.

Openness merupakan sifat kepribadian yang dikarakteristikkan sebagai imajinatif dan berwawasan luas, memiliki ketertarikan kepada aspek yang luas, dan rasa ingin tahu yang tinggi kepada orang lain. Agreeableness merupakan sifat kepribadian yang meliputi atribut percaya, altruisme, melakukan kebaikan, afeksi, dan berbagai perilaku prososial lainnya.

Emotional stability merupakan sifat kepribadian yang cenderung lebih stabil dan lebih tangguh secara emosional. Apabila emotional stability rendah, maka cenderung ke sifat kepribadian neuroticism yang merupakan lawan dari stabilitas emosi ${ }^{14}$.

Penelitian sebelumnya selama dua dekade (20 tahun) terakhir di luar negeri seringkali memperlihatkan asosiasi antara traits personality dan service orientation. Namun, setiap penelitian memperlihatkan kesimpulan yang berbeda. Sifat kepribadian mana saja yang berasosiasi secara signifikan dengan sikap melayani. Frei \& McDaniel (1998) menemukan agreeableness, emotional stability, conscientiousness berhubungan positif dengan service orientation ${ }^{15}$. Chait dkk (2000) menemukan sifat extraversion, conscientiousness, openness berkorelasi positif terhadap service orientation ${ }^{16}$. Costen dan Barrash (2006) menemukan conscientiousness, agreeableness, dan extraversion berhubungan positif dengan service orientation ${ }^{17}$.

Carraher dkk (2009) menemukan semua sifat kepribadian kecuali neuroticism berhubungan positif terhadap service orientation $^{18}$. Serceoglu (2013) juga, menemukan semua sifat kepribadian kecuali neuroticism berhubungan positif dengan service orientation ${ }^{19}$. Ceyhun dan Diker (2016) menemukan sifat conscientiousness, agreeableness, dan openness berkorelasi positif dengan service orientation ${ }^{20}$.

Kim \& Lee (2016) menemukan semua sifat kepribadian berhubungan dengan service orientation dan conscientiousness lah sifat yang paling berhubungan ${ }^{21}$. Tekin dan Kalkan (2017) hanya menemukan openness satusatunya yang berhubungan positif dengan service orientation $^{22}$. Lalu Kosker dkk (2019) menemukan agreeableneess merupakan sifat kepribadian yang memiliki pengaruh terkuat terhadap service orientation ${ }^{6}$.

Untuk faktor interpersonal, dukungan sosial dapat membantu tenaga kesehatan untuk meningkatkan kualitas pelayanan mereka $^{23}$. Berbagai dukungan sosial (teman, rekan sejawat, keluarga, masyarakat) 
umumnya membantu tenaga kesehatan tetap fokus mengatasi pekerjannya pada situasisituasi yang sulit ${ }^{24}$. Tenaga kesehatan memasukkan interaksi dengan temantemannya sebagai personal resource yang menurut riset dapat meningkatkan customer orientation sebagai mekanisme disaat situasi sulit $^{13}$. Dukungan sosial juga meningkatkan pengaruh dari sikap kepemimpinan nakes untuk lebih peduli terhadap service orientation $^{12}$.

Riset lain mengatakan bahwa high performance dan baiknya kualitas layanan nakes umumnya karena pengaruh dukungan sosial dan budaya organisasi ${ }^{25}$. Fasilitas rumah sakit perlu meningkatkan kerjasama antar nakes ataupun juga membantu dukungan sosial mereka untuk meningkatkan customer orientation $^{12}$. WHO sendiri mendorong agar nakes dapat dengan mudah mengakses sumber dukungan sosial dan fasilitas kesehatan mental untuk kesejahteraan psikologis. Tenaga kesehatan yang sehat mental akan lebih baik dalam menangani pasien di saat situasi yang sulit ${ }^{26}$.

Di Indonesia sendiri, masih minim riset yang meninjau seberapa jauh lima traits personality atau sifat kepribadian dan dukungan sosial mampu memprediksi service orientation di bidang kesehatan. Jenis penelitian replikasi dan lanjutan perlu dilakukan karena bahkan, diantara penelitianpenelitian terkait selama puluhan terakhir tidak ada yang memiliki pola yang sangat mirip dan bertul-betul sama. Penelitian ini diharapkan mampu meningkatkan berbagai peran traits personality dan dukungan sosial secara teoritis dan praktis untuk meningkatkan service orientation. Khususnya service orientation tenaga kesehatan di Indonesia, yang dapat berdampak terhadap kepuasan dan loyalitas pasien, serta pengalaman-pengalaman positif yang dialami pasien.

\section{METODE PENELITIAN}

Penelitian ini menggunakan pendekatan kuantitatif, dengan metode penelitian crosssectional serta menggunakan serangkaian teknik statistik regresi linear untuk melihat koefisien determinasi (R2) variable independen. Cozby dan Bates (2015) menjelaskan bahwa metode cross-sectional merupakan pengembangan penelitian di mana orang-orang dari berbagai umur dipelajari dalam satu titik waktu. Penulis kemudian melihat seberapa tinggi koefisien determinasi (R2) dengan serangkaian teknik statistik regresi linear untuk melihat seberapa jauh variabel-variable independen berkontribusi terhadap variabel dependen.

Uji korelasional juga digunakan untuk menambah hasil penelitian. Adapun studi korelasi berusaha untuk mempelajari hubungan yang telah diobservasi/diukur dengan beragam variable yang diinginkan. Hal ini dapat diukur dengan meminta partisipan mendeskripsikan perilakunya, dapat juga dengan mengamati secara langsung perilaku, mencatat respon fisiologis, atau bahkan memeriksa berbagai catatan statistik seperti data sensus. Umumnya, jenis nonparametric test dapat digunakan untuk mengukur hubungan antar variable pada data ordinal ataupun nominal ${ }^{27}$.

\section{Pengumpulan data}

Teknik sampling pada penelitian ini menggunakan convenience sampling. Yang berarti, sampel didapatkan berdasarkan ketersediaan sumber daya dan kemudahan untuk mendapat atau menjangkau partisipan. Jumlah partisipan yang bersedia mengisi kuesioner pada penelitian ini adalah 218 tenaga kesehatan yang aktif di rumah sakit, puskesmas, klinik, dan apotek. Minimal partisipan untuk mencapat taraf signifikan $\mathrm{p}=0,05$ berdasakan perangkat lunak $G$-power 3.1 adalah 146 partisipan, sehingga telah memenuhi persyaratan.

\section{Karakteristik Partisipan}

Tenaga kesehatan (nakes) pada penelitian ini sesuai dengan definisi nakes pada UU nomor 36 tahun 2014. Yaitu setiap individu yang telah mengabdikan diri dalam bidang kesehatan, mempunyai pengetahuan, dan/atau keterampilan melalui pendidikan di bidang kesehatan. Berdasarkan UU tersebut, nakes terdiri dari beragam profesi dengan peran yang berbeda-beda. Adapun pada penelitian ini, terfokus pada partisipan yang aktif di rumah sakit, klinik, apotek, lembaga dan puskesmas. 


\section{Instrumen Penelitian}

Untuk mengukur personality traits, peneliti menggunakan IPIP-BFM-25. IPIPBFM-25 memiliki 25 butir item berbentuk 5point scale yang telah diadaptasi secara budaya oleh Akhtar dan Azwar (2018). Skala ini awalnya dikembangkan oleh Goldberg tahun 1992 dengan jumlah item lebih banyak. Setiap dimensi IPIP-BFM-25 memiliki total lima (5) item. Hasil penelitian Akhtar dan Azwar (2018) memperlihatan kelima dimensi personality traits memiliki koefisien reliabilitas diatas .70 dengan pendekatan testretest ${ }^{28}$.

Service orientation diukur dengan menggunakan Costumer orientation scale oleh Brown (2002) yang memiliki 12 butir item dengan bentuk 5 point-scale ${ }^{5}$. Di Indonesia, skala ini telah diuji reliabilitasnya pada sample perawat oleh Siagian (2017) dengan jumlah sample 84 perawat di Semarang ${ }^{29}$. Hasil nilai konsistensi internalnya yakni 0.886 yang cukup reliable untuk digunakan dalam penelitian.

Menurut Akandere (2015), instrument penelitian yang sering digunakan untuk mengukur service orientation adalah alat ukur dari costumer service orientation; misalnya Brown dkk., tahun 2002, Donavan dkk., tahun 2004, Hennig-Thurau, dll ${ }^{30}$. Hal tersebut karena customer orientation sama halnya dengan service orientation pada level individu, yang mana para ahli melihat konsep ini merupakan karakteristik kepribadian yang terlihat di permukaan pada kehidupan seharihari $^{5-6}$.

Dukungan sosial yang diterima nakes diukur dengan menggunakan Multidimensional Scale Perceived Social Support atau MPSS, merupakan alat ukur yang dikembangkan oleh Zimet (1988), berjumlah 12 item dan berbentuk 4 pointscale $^{31}$. Terdiri atas tiga dimensi: dukungan teman, keluarga, teman terdekat atau sahabat. Di Indonesia, skala ini telah diuji reliabilitasnya oleh Asih dkk (2019) dengan nilai cronbach alpha mencapai $.952^{24}$. Sampel dalam penelitian mereka adalah perawat.

Setelah terkumpul 218 partisipan tenaga kesehatan yang aktif, peneliti berusaha melihat reliabilitas setiap dimensi istrumen penelitian. Didapatkan reliabilitas: conscientiousness .771, extraversion .647, agreeablesness .760, emotional stability .776, openness .627 pada IPIP-BFM-25. Service orientation .871 pada Costumer Orientation Scale. Serta dukungan sosial .866 pada MPSS.

\section{HASIL DAN PEMBAHASAN}

Partisipan pada penelitian ini adalah tenaga kesehatan yang aktif di rumah sakit, puskesmas, klinik, dan apotek. Didapatkan total partisipan 218 dengan data lengkap dan memenuhi persyaratan penelitian. Sebagian besar partisipan adalah perempuan sebanyak 167 (76,60\%), sedangkan laki-laki 51 $(23.40 \%)$. Rentang usia partisipan dari 18 hingga 72 tahun, dengan rata-rata usia 30 tahun dan standar deviasi 7.89.

Tabel 1. Pekerjaan/Profesi responden penelitian

\begin{tabular}{|c|c|c|c|}
\hline NO & Pekerjaan & $f$ & $\%$ \\
\hline 1 & Perawat & 89 & $40.8 \%$ \\
\hline 2 & Bidan & 37 & $16.8 \%$ \\
\hline 3 & $\begin{array}{c}\text { Karyawan } \\
\text { umum/ASN }\end{array}$ & 18 & $8.3 \%$ \\
\hline 4 & $\begin{array}{l}\text { Relawan } \\
\text { Covid }\end{array}$ & 18 & $8.3 \%$ \\
\hline 5 & $\begin{array}{l}\text { Dokter } \\
\text { Umum }\end{array}$ & 14 & $6.5 \%$ \\
\hline 6 & $\begin{array}{c}\text { Bagian } \\
\text { Administrasi }\end{array}$ & 12 & $5.5 \%$ \\
\hline 7 & Apoteker & 5 & $2.3 \%$ \\
\hline 8 & Laboran & 4 & $1.8 \%$ \\
\hline 9 & Dokter gigi & 4 & $1.8 \%$ \\
\hline 10 & $\begin{array}{l}\text { Promotor } \\
\text { Kesehatan }\end{array}$ & 3 & $1.4 \%$ \\
\hline 11 & $\begin{array}{l}\text { lain-lain } \\
\text { TOTAL }\end{array}$ & $\begin{array}{c}14 \\
218\end{array}$ & $\begin{array}{r}6.5 \% \\
100 \%\end{array}$ \\
\hline
\end{tabular}

Penulis pertama-tama melakukan uji korelasi untuk melihat hubungan antar variable secara signifikan. Uji korelasi yang digunakan adalah spearman correlation 2 tailed.

Tabel 2. Hasil uji korelasi tiap variabel terhadap service orientation

\begin{tabular}{lcc}
\hline & \multicolumn{2}{c}{ Service orientation } \\
\cline { 2 - 3 } & $\begin{array}{c}\text { Koefisien } \\
\text { korelasi }\end{array}$ & $\begin{array}{c}\text { sig. } \\
(\mathrm{p})\end{array}$ \\
\cline { 2 - 3 } Openness & $\mathbf{. 4 8}^{* *}$ & .000 \\
Conscientiousness & $\mathbf{. 4 3}^{* *}$ & .000 \\
Extraversion & $\mathbf{. 2 3}^{* *}$ & .000
\end{tabular}




\begin{tabular}{lcc} 
Agreeableness & $\mathbf{. 4 7} * *$ & .000 \\
Emotional Stability & .127 & .061 \\
Dukungan Sosial & $.431 * *$ & .000 \\
\hline
\end{tabular}

Ket: $* *=p<0.01$

Pada tabel diatas, dapat dilihat bahwa service orientation nakes pada penelitian ini berkorelasi signifikan dengan semua personality traits dan dukungan sosial kecuali emotional stability. Personality traits yang memiliki korelasi tertinggi adalah sifat kepribadian agreeableness, lalu disusul conscientiousness, extraversion, dan terakhir openness.

Hasil korelasi ini sejalan dengan penelitian sebelumnya diluar Indonesia yang memperlihatkan sifat kepribadian agreeableness dan conscientiousness yang seringkali berkorelasi dengan service orientation. Kemudian disusul dengan extraversion, dan openness ${ }^{6,18,20,21}$.

Sehingga, dapat disimpulkan bahwa semakin tinggi kecenderungan seseorang memiliki sifat-sifat kepribadian seperti agreeableness, conscientiousness, extraversion, serta openness, maka service orientation juga semakin naik dengan kekuatan korelasi sedang (berkisar .248 hingga .474), begitu pun sebaliknya. Dukungan sosial yang diterima partisipan juga. apabila semakin tinggi maka kualitas service orientation juga semakin naik dengan kekuatan korelasi sedang (.431), begitu pun sebaliknya.

Tabel 3. Model regresi linear personality traits sebagai variable independen terhadap service orientation

\begin{tabular}{lccccc}
\hline \multicolumn{1}{c}{ Personality Traits } & R & R2 adjusted & F & $\boldsymbol{\beta}$ & t \\
\hline Openness & & & & .015 & .091 \\
Conscientiousness & & & & .469 & $\mathbf{3 . 6 8 9 * *}$ \\
Extraversion & .570 & .309 & $\mathbf{2 0 . 3 9 5 * *}$ & .074 & .635 \\
Agreeableness & & & & .857 & $\mathbf{5 . 4 7 2 * *}$ \\
Emotional Stability & & & & .134 & 1.502 \\
\hline
\end{tabular}

Ket: $* *=\mathrm{p}<0,01, *=\mathrm{p}<0,05$

Untuk model regresi, berdasarkan signifikansi nilai $\mathrm{F}(\mathrm{p}<0,01)$ dapat dikatakan bahwasanya kelima personality traits secara bersama-sama atau simultan mampu mempengaruhi secara signifikan service orientation nakes ( $\mathrm{R}=.570, \mathrm{R} 2$ adjusted .309). Adapun koefisien determinasi model regresi sebesar .309. Berarti, variable personality traits mampu menjelaskan varians kecenderungan service orientation sebesar $30,9 \%$. Kemudian sisanya $68,1 \%$ dijelaskan dengan faktor lainnya diluar model regresi ini.

Namun, hanya dua dari lima sifat kepribadian yang signifikan $(\mathrm{p}<0,01)$ mempengaruhi service orientation apabila sendiri-sendiri, yaitu sifat agreeableness $(t=5.472 * *) \quad$ dan sifat conscientiousness $\left(\mathrm{t}=3.689^{* *}\right)$. Sifat Agreeableness pada model regresi memiliki koefisien beta tertinggi $(\beta=.867)$. Disusul dengan sifat conscientiousness $(\beta=469)$, Sehingga, dapat dikatakan bahwa kedua sifat atau traits kepribadian merupakan faktor yang mempengaruhi service orientation.

Tenaga kesehatan yang aktif pada industri layanan perlu memperlihatkan minat yang besar pada orang lain, peduli dengan orang lain, merasakan empati dan caring, menikmati proses membantu dan berkontribusi pada kebahagiaan orang lain, dan membantu pekerjaan orang lain yang merupakan kecenderungan dari sifat kepribadian agreeableness ${ }^{32}$. Sifat-sifat tersebut diharapkan dapat meningkatkan kualitas service orientation yang ada di industri layanan kesehatan (rumah sakit, klinik, apotek, dan puskesmas).

Mereka juga membutuhkan sifat-sifat seperti perhatian tingkat tinggi, kontrol impuls yang baik, mempersiapkan diri, menyelesaikan tugas dengan segera, perhatian dengan detail, senang memiliki jadwal yang ditetapkan yang merupakan indikator dari sifat kepribadian conscientiousness ${ }^{14,32}$. Sifat kepribadian tersebut perlu diperhatikan untuk 
meningkatkan kualitas service orientation nakes pada tingkat individual.

Tabel 4. Model regresi dukungan sosial sebagai variable independen terhadap service orientation

\begin{tabular}{cccccc}
\hline Dukungan Sosial & R & R2 adjusted & F & $\boldsymbol{\beta}$ & t \\
\hline Dukungan Keluarga & & & & .292 & $\mathbf{1 . 9 7 1 *}^{*}$ \\
Dukungan Teman & .421 & .166 & $\mathbf{1 5 . 3 5 4 * *}$ & .421 & 1.829 \\
Dukungan Sahabat & & & & .395 & $\mathbf{2 . 6 6 3}^{* *}$ \\
\hline
\end{tabular}

Ket: $* *=p<0,01 *=p<0,05$ 
Berdasarkan tabel 4, nilai $\mathrm{F}$ hitung variable dukungan sosial memiliki signifikansi $\mathrm{p}<0,01$ dengan koefisien R2 sebesar .166. Hasil ini menunjukkan bahwa dukungan sosial secara bersama-sama atau simultan berpengaruh secara signifikan terhadap service orientation. Sebesar 16,6\% varians service orientation dapat dijelaskan oleh dukungan sosial dan 83,4\% varians service orientation dijelaskan oleh faktor lain diluar model. Sehingga, semakin tinggi dukungan sosial yang diterima dan dipersepsikan tenaga kesehatan, maka dapat mempengaruhi kualitas service orientation ke arah positif.

Apabila ketiga dimensi dukungan mempengaruhi sendiri-sendiri, dukungan dari keluarga memiliki koefisien beta tertinggi $(\beta=.421)$ namun, tidak mencapai taraf signifikan 0,05. Disusul dengan dukungan sahabat $(\beta=395)$ lalu dukungan teman $(\beta=.292)$. Adapun dimensi sahabat dan teman secara signifikan mempengaruhi service orientation nakes $(\mathrm{p}<0,05)$. Dengan demikian, untuk meningkatkan kualitas service orientation di saat situasi pandemi COVID-19 sekarang, tenaga kesehatan membutuhkan dukungan sosial yang terdekat, khususnya dari sahabat dan juga teman sehari-hari.

Dukungan sosial yang diterima oleh tenaga kesehatan umumnya berasal dari keluarga, teman, dan rekan sejawat. WHO sendiri mendorong agar para tenaga kesehatan dapat mengakses sumber dukungan sosial dan fasilitas kesehatan mental dengan mudah untuk meningkatkan kesejahteraan psikologis mereka $^{26}$. Usaha agar nakes tetap memiliki hubungan dekat dengan supporting group mereka akan memungkinkan nakes lebih resilient, mengatur kelelahan fisik lebih mudah, fokus, kemudian lebih berkontribusi sesuai kemampuan mereka masing-masing dalam situasi yang sulit ${ }^{24,33,34}$.

Penelitian sebelumnya yang memperlihatkan model regresi dimana agreeableness dan coscientiousness mempengaruhi secara signifikan adalah Kosker dkk (2019) yang memperlihatkan semua sifat kepribadian signifikan mempengaruhi dengan sample partisipan mahasiswa hospitality di Turki. Hasilnya juga cukup mirip dimana agreeableness lah yang memiliki koefisien beta terbesar terhadap service orientation ${ }^{6}$.

Ada beberapa studi korelasional yang memperlihatkan kedua traits agreeableness maupun conscientiousness seringkali berkorelasi dengan service orientation dengan sampel partisipan yang berbeda. Diantaranya Frei dan McDaniel (1998), ditambah dengan emotional stability, Donavan (1999) ditambah dengan extraversion dan neuroticism, Costen dan Barrash (2006) ditambah dengan extraversion, Periatt dkk (2006) ditambah dengan emotional stability dan openness, Ceyhun dan Diker (2016) ditambah dengan openness. Kualitas service orientation pada level individu sendiri umumnya dikaitkan dengan gambaran dan sifat kepribadian tertentu yang mampu meningkatkan keinginan lebih pegawai agar tetap fokus dan perhatian pada kebutuhan-kebutuhan pelanggan ${ }^{10,15,17,21,35}$.

Dalam penelitian ini, terdapat limitasi yang bisa dijadikan concern untuk penelitian selanjutnya. Dari segi data, penelitian ini tidak mengumpulkan gambaran mengenai berbagai budaya organisasi partisipan, dimana partisipan bekerja dan rating-nya menurut pasien, kemudian sejauh mana tempat kerja nakes memiliki fasilitas-fasilitas dalam bentuk fisik yang dapat mempengaruhi persepsi pasien terhadap service orientation. Penelitian ini juga hanya mengumpulkan data satu kali. Untuk penelitian selanjutnya, peneliti dapat melakukan berbagai metode dan jenis penelitian yang berbeda, mengumpulkan data dengan rentang waktu yang berbeda, karekteristik individual lebih detail, serta lebih mendasarkan pada beragam manfaat teoritis dan praktis yang lebih bermanfaat.

\section{KESIMPULAN}

Hasil penelitian memperlihatkan peningkatan kualitas traits personality dan juga kualitas dukungan sosial yang diterima dapat memprediksi secara signifikan kualitas-kualitas dari service orientation tenaga kesehatan (nakes). Semakin tinggi pengaruh dari 
personality traits, maka semakin tinggi juga kualitas service orientation. Kemudian semakin tinggi pengaruh dari dukungan sosial, semakin tinggi juga kualitas service orientation dari tenaga kesehatan (nakes). Pada faktor intrapersonal, diketahui bahwa sifat atau traits kepribadian agreeableness dan conscientiousness lah yang dapat memprediksi service orientation nakes lebih baik daripada sifat kepribadian lainnya. Sedangkan pada dukungan sosial, yang berasal dari sahabat dan teman dapat memprediksi service orientation apabila sendiri-sendiri.

Agreeableness meliputi atribut seperti percaya, altruisme, berbuat baik, kasih sayang, dan perilaku prososial lainnya. Orang-orang yang cenderung tinggi dalam agreeableness cenderung lebih kooperatif (Cherry, 2019). Orang dengan skor tinggi pada sifat cosncientiousness cenderung terorganisir. memperhatikan detail, membuat rencana ke depan, cenderung memperhatikan jadwal, senang mempersiapkan diri, menyelesaikan tugas dengan segera, perhatian dengan detail. Sedangkan pada low scores cenderung tidak menyukai hal yang terstruktur dan jadwal, membuat kekacauan dan tidak mengurus banyak hal, menunda tugas, seringkali tidak mengerjakan tugas secara tuntas (Power \& Pluess, 2015).

selain melihat sifat kepribadian dari nakes, mutu pelayanan juga diperkuat dengan meningkatkan relasi positif antar nakes atau sumber-sumber dukungan sosial mereka (keluarga dan sahabat) sebagai langkah peningkatan service orientation pada level individu

\section{UCAPAN TERIMA KASIH}

Terima kasih kami ucapkan kepada seluruh partisipan yang bersedia membantu penelitian. Dan juga kepada pembimbing dan reviewer atas seluruh bantuannya. Adapun artikel ini bebas dari kepentingan pihak tertentu.

\section{DAFTAR PUSTAKA}

1. Yulianti, A. (2020). Tingkatkan mutu layanan kesehatan, selamatkan Bangsa dari Pandemi Covid-19. Diakses di www.mutupelayanankesehatan.net

2. Popli, S., \& Risvi, A.I. (2015). Exploring the relationship between service orientation, employee engagement and perceived leadership style: a study of managers in the private service sector organizations in India. Journal of Services Marketing

3. He, H., Wang, W., Zhu, W., \& Harris, L. (2015). Service workers' job performance: The roles of personality traits, organizational identification, and customer orientation. European Journal of Marketing, 49(11-12), 1751-1776.

4. Solimun, Fernandes, R.A. (2017) The mediation effect of customer satisfaction in the relationship between service quality, service orientation, and marketing mix strategy to customer loyalty. Journal of management development vol. 34 no. 1, 2018

5. Brown, T.J., John, C.M., Tood, D., \& Jane, W.L (2002) The customer orientation of service worker: personality trait effect on self-and supervisor performance ratings. Journal of Marketing Research 39, 110119

6. Kosker, H., Unur K, \& Gurso, D (2019). The effect of basic personality traits on service orientation and tendency to work in the hospitality and tourism industry. Journal of teaching in travel and tourism.

7. Kim, J.H. (2011) Service Orientation, Service Quality, Customer Satisfaction, and Customer Loyality: Testing a Structural Model. Journal of Hospitality Marketing \& Management vol. 20. 2011

8. Yang J.H, Kim, D.H., \& Chang, D.M. (2010). The impact of personality type and job satisfaction on customer oriented behavior of working people in hospitals. Health Soc Sci. 2010;28(1):115e38.

9. Yoon, J.S., Choi, C.D., \& Park, W.J (2007) Service Orientation: Its Impact on Business Performance in the Medical Service 
Industry. The service Industries Journal Vol. 272007

10. Periatt, J.A., Subhra, C., \& Stephen A.L (2007) Using Personality Traits to Select Customer-Oriented Logistics Personnel. Transportaion Journal 46(1): 22-37

11. Prentice C, Trait EI. (2012). Customer orientation and service performance. Open Access Scientific Rep. 2012; 1:369

12. Bruno, A., Dell'Aversana, G., \& Zunino A. (2017). Customer Orientation and Leadership in the Health Service Sector: The Role of Workplace Social Support. Front. Psychol. 8:1920

13. Gountas, S., \& Gountas, J. (2015). How the 'warped' relationships between nurse emotions, attitudes, social support, and perceived organizational conditions impact costumer orientation. JAN Original Research: Empirical Research Quantitative. England: John Wiley \& Sons Ltd.

14. Power RA, Pluess, M. (2015) Heritability estimates of the Big Five personality traits based on common genetic variants. Transl Psychiatry.

15. Frei, Richard L. and Michael A. McDaniel. 1998. "Validity of Customer Service Measures in Personnel Selection: A Review of Criterion and Construct Evidence." Human Performance 11(1):127.

16. Chait, N. H., Carraher, M. S., \& Buckley, R. (2000). Measuring service orientation with biodata. Journal of Managerial Issues, 12(1), 109-120.

17. Costen, W.M., \&. Barrash D.I. (2006). ACE-ing the Hiring Process: A Customer Service Orientation Model. Journal of Human Resources in Hospitality \& Tourism 5(1):35-49.

18. Carracher, S. M., Parnell, J. A., \& Spillan, J. E. (2009). Customer service-orientation of small retail business owners in Austria, The Czech Republic, Hungary, Latvia, Slovakia, and Slovenia. Baltic Journal of Management, 4(3), 251-268.

19. Serceoglu, N. (2013). The effect of characteristic of employees who work in hospitality on service orientation. Journal of Yasar University, 8(31), 5253-5273

20. Ceyhun, S., \& Diker, O. (2016). Effects of personality traits of sports-health center employees on service orientation in province of Ankara. Niğde Universty Journal of Physical Education and Sport Sciences, 10(1), 100-110.

21. Kim, B., Lee, J. (2016) Relationships between Personal Trait, Emotional Intelligence, Internal Marketing, Service Management, and Customer Orientation in Korean Outpatient Department Nurses. Asian Nurse Research vol. 10, 18-24

22. Tekin, A.O., \& Kalkan, Gurkan (2017) The Relationship Between Service Orientation and Five Factor Personality Traits: A Study on Hotel Employees. Journal of Yasar University 12/48, 272-283

23. Nicola, M. (2014). Nurses must support each other: Nursing Times. Nursing Week News; Nov 11, 2014; 110-45; ProQuest pg.3

24. Asih, R.O., Fahmy, R., Novriada, D., Lucida, H., Priscilla, V., \& Putri M.Z. (2019) Cross Sectional: Dukungan sosial dan resiliensi perawat. Jurnal Ilmiah Batanghari Jambi 19(2):421-425

25. Vandenburghe C., Michon R., Tremblay M., Bentein K., Chebat J.C. \& Fils J.F. (2007). An examination of the role of perceived support and employee commitment in employee-customer encounters. Journal of Applied Psychology 92, 1177-1187.

26. WHO. (2020). Keep health workers safe to Keep patients safe: WHO. Diakes di https://www.who.int

27. Sekaran, U., \& Boigie, R. (2016). Research Methods for Business: A Skill Building Approach 7th edition. United Kingdom, John Wiley \& Sons Ltd

28. Akhtar, H. \& Azwar, S. (2018). Development and Validation of a Short Scale for Measuring Big Five Personality Trait: The IPIP-BFM-25 Indonesia. Journal of Innovation in Psychology, Education and Didactics. 22(2), 167-174 
29. Siagian, S.N (2017) Korelasi Antara SelfMonitoring dan Customer Orientation Pada Perawat di Rumah Sakit. Yogyakarta: Prodi Psikologi Universitas Sanata Dharma

30. Akandere, G. (2015). The impact of service orientation as personality traits on job satisfaction and intention to leave: a research in the logistic companies. Vienna: 17 th International Academic Converence.

31. Zimet, G. D., Dahlem, N. W., Zimet, S. G. \& Farley, G. K. (1988). The multidimensional scale of perceived social support, Journal of Personality Assessment. 52(1) 30-41.

32. Cherry, K. (2019). The Big Five Personality Traits. Diakses di Www.verywell.com

33. Yunita, P. I., \& Kismono, G. (2014) Influence of Work-Family Conflict and Family Work Conflict on Employees Turnover Intentions with Gender, Social Support and Individual Value Moderating Effects. Journal of Indonesian Economy and Business, 29(1)

34. Wang, L., Tao, H., Bowers, J.B., \& Brown, R. (2017). Influence of Social Support and Self-Efficacy on Resilience of Early Career Registered Nurses. Westren Journal of Nursing Research vol. 40(10)

35. Donavan, D.T. (1999). Antecedents and Consequences of the Contact Empoloyee's Service Orientation: From a Personality Traits to Service Behaviors. PhD Dissertation, Oklahoma State University. 